\title{
Bending strength and phase composition of cement stone subjected to loading at an early stage
}

\author{
Yuriy Galkin ${ }^{1, *}$, and Sergey Udodov ${ }^{1}$ \\ ${ }^{1}$ Kuban state technological university, 350072 Krasnodar, Russia
}

\begin{abstract}
The article deals with the results of comparative tests of the phase composition of cement stone distinguished by strength under bending and compression. The comparison has been made between samples subjected to early loading and control samples. An increase in tensile strength in bending of samples subjected to early loading was recorded. The difference in compressive strengths does not exceed 5\%. X-ray phase analysis indicates amorphous phase increase with the growth of strength properties, which is manifested in increased intensity of the amorphous phase arc in the X-ray diffraction pattern. The highest peak of the curve corresponds to the maximum flexural strength of the entire row of samples. Among the samples subjected to early loading, the peak intensity of the group of crystal tobermorites with interplanar distances $11.5-11.3 \AA$ and $12.5 \AA$ appeared to be higher than the intensity of the control samples. It was proposed that the amorphous structure affects the increase in tensile strength in bending of cement stone subjected to early loading.
\end{abstract}

\section{Introduction}

Accelerated erection of buildings and structures from reinforced concrete has always been one of the highest priorities for construction industry. The paper of A.V. Satalkin [1] published in 1956 describes one of the first work experiences in the implementation of early loading in the course of erection of bridge span structures. Since then there have been many papers devoted to study of the properties of cement systems and composites subjected to early loading, (see [2-9]). Besides, concrete studies consider the properties of the cement at the later stages [10-15]. In the previous papers [16-17] we revealed an increase in flexural strength occurred in the samples subjected to early loading. The incremental growth reached $21 \%$ for Portland cement compounds. The change in compressive strength was less significant and did not exceed $10-15 \%$

The purpose of the paper is research of strength properties of cement stone from various batches subjected to early loading in regard with the phase composition. The study posed the following tasks:

1) determine the strength characteristics of samples loaded at early stage under bending and compression;

\footnotetext{
* Corresponding author: tcmii@mail.ru
} 
2) obtain X-ray diffraction patterns of the samples subjected to loading and control samples while holding thermal analysis;

3) overlay XRF curves within each batch and review phase analysis with regard to different strength characteristics;

4) make a general RFA with plotting for each sample;

5) compare derivatograms of loaded and control samples;

6) establish differences between structures and determine its relationship with the obtained strength data.

\section{Methods}

Binder to be applied - Portland cement "Verhnebakanskij" Cem I 42,5 H as per GOST 31108. Chemical composition is given in the Table 1.

Table 1 Chemical and mineral composition of applied Portland cement

\begin{tabular}{|l|l|l|l|l|l|l|l|l|l|l|l|}
\hline \multicolumn{9}{|c|}{ Chemical composition, \% } & \multicolumn{4}{c|}{ Mineral composition, \% } \\
\hline $\mathrm{SiO}_{2}$ & $\mathrm{Al}_{2} \mathrm{O}_{3}$ & $\mathrm{Fe}_{2} \mathrm{O}_{3}$ & $\mathrm{CaO}$ & $\mathrm{MgO}$ & $\mathrm{SO}_{3}$ & $\mathrm{R}_{2} \mathrm{O}$ & $\mathrm{TiO}_{2}$ & $\mathrm{C}_{3} \mathrm{~S}$ & $\mathrm{C}_{2} \mathrm{~S}$ & $\mathrm{C}_{3} \mathrm{~A}$ & $\mathrm{C}_{4} \mathrm{AF}$ \\
\hline 21 & 4,36 & 4,16 & 64,7 & 0,46 & 3 & 0,62 & - & 61 & 17 & 7 & 15 \\
\hline
\end{tabular}

Cement age for load application has been designated in accordance to Figure 1 [16] and is equal to 6 days. For this cement age increase of tensile strength in bending has been the highest, as it mentioned previously [16]. Duration of load application is equal to 7 days. There were two batches of samples being loaded (three prisms in each batch). Water-cement ratio was 0.3 . Pressure load stood at $30 \%$ of cement stone prism strength in the age of loading, which was calculated as the arithmetic mean of 3 values of strength. The surface hasn't been isolated. Control samples were hardening under the same temperature and humidity conditions as the loaded ones $\left(\mathrm{t}=21-22^{\circ} \mathrm{C}, \varphi=55-60 \%\right)$.

\section{Results and discussion}

Arithmetic means of compression strength of samples with the fixed composition produced as per GOST 310.4, are given in the Table 2. The results were processed using statistical analysis techniques. X-ray patterns of the control samples are shown in Fig. 1, patterns for the samples subjected to loading - in Fig. 2.

Table 2 Compression strength of samples subjected to early loading

\begin{tabular}{|c|c|c|c|c|}
\hline & \multicolumn{2}{|c|}{ Control } & \multicolumn{2}{c|}{ Loaded on the $6^{\text {th }}$ day } \\
\hline Sample number & 1 & 2 & 1 & 2 \\
\hline Flexural strength, $\mathrm{mPa}$ & 4,25 & 4,67 & 5,36 & 5,74 \\
\hline Compression strength, $\mathrm{mPa}$ & 44,4 & 45,6 & 43,45 & 42,7 \\
\hline
\end{tabular}

According to the data given in the Table 2 samples 1 and 2 have nearly the same compression strength. Flexural strength is higher for the cement stone of sample 2. By overlaying X-ray patterns we reveal displacement of amorphous phase arc of sample 2 within the angle range $2 \Theta=5-13^{\circ}$ toward a higher intensity of diffraction peaks. It may indicate that the structure is more amorphous [18]. Main phase - Tricalcium silicate $\mathrm{C}_{3} \mathrm{~S}$ - is represented within the range $2 \Theta=22,98^{\circ} ; 29,44^{\circ} ; 32,12^{\circ} ; 32,5^{\circ} ; 34,24^{\circ} ; 34,9^{\circ} ; 36,6^{\circ} ; 38,82^{\circ} ; 41,18^{\circ}$. The highest peaks of the amorphous crystalic hydrates $\mathrm{CSH}$ [19-20] in the X-ray diffraction patterns are seen in $2 \Theta=7,52^{\circ} ; 7,86^{\circ} ; 8,6^{\circ} ; 9,6^{\circ} ; 10,54^{\circ} ; 11,78^{\circ} ; 13,94^{\circ} ; 14,76^{\circ} ; 25,64^{\circ}$; 
$29,94^{\circ} ; 30,92^{\circ}$. There are also plotting of Portlandite $\mathrm{CH}\left(\right.$ from $\left.2 \Theta=17,94^{\circ} ; 28,58^{\circ} ; 34,12^{\circ}\right)$ and calcium aluminate sulfate trihydrate (ettringite), given in angles $2 \Theta=9,04^{\circ} ; 15,7^{\circ}$; $18,8^{\circ} ; 22,82^{\circ} ; 34,9^{\circ}$.

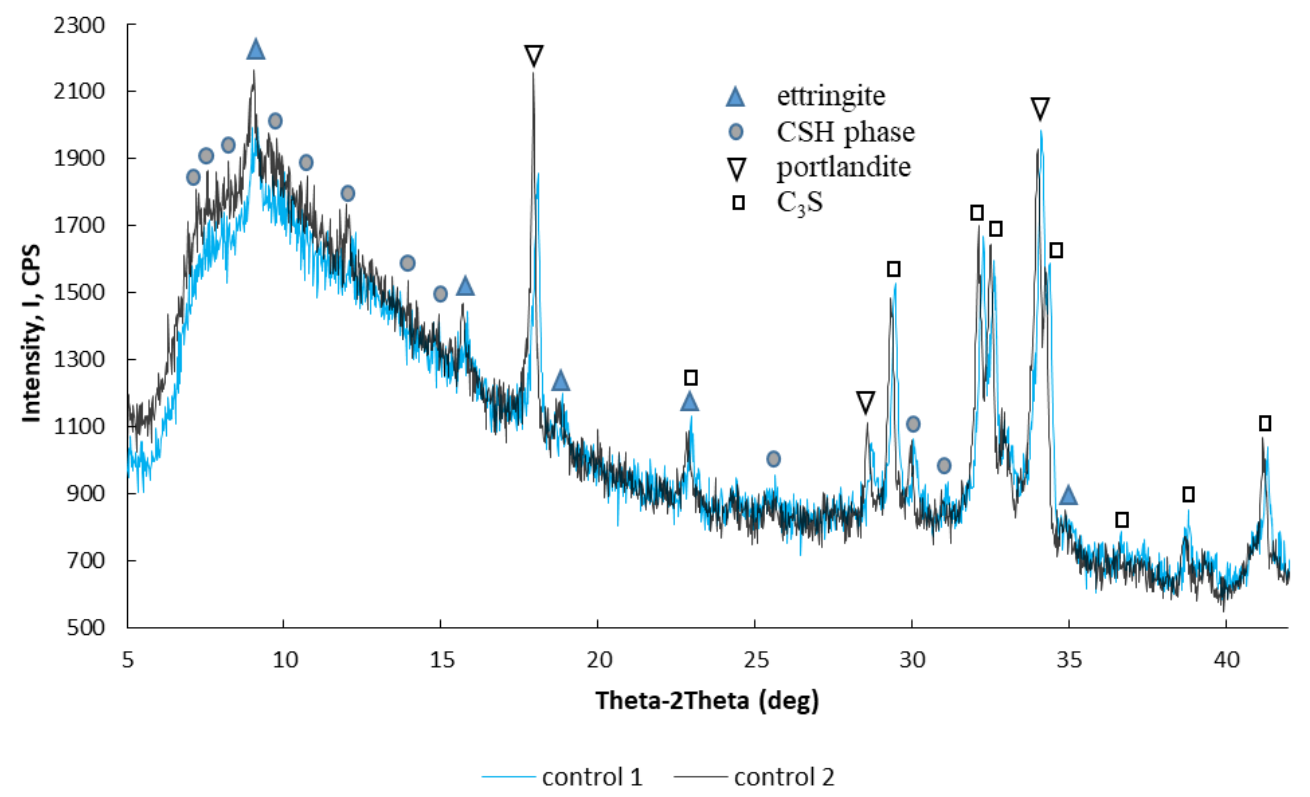

Fig. 1 X-ray diffraction patterns of control samples (strength characteristics are given in the Table 2)

By reviewing Figure 1 and taking into account the difference in flexural strength (it was higher for control sample № 2 - see Table. 2), the following may be noted:

- for sample №2 with the highest value of Rtb the main peak of Portlandite at $2 \Theta=17,94^{\circ}$ [20] is more intensive. It may be due to higher degree of hydration of silicate minerals, as this value is one of the criteria of hydration process [21];

- ettringite peak at $2 \Theta=9,04^{\circ}$ for sample №2 is displaced higher, and its width is narrower in comparison with the peak of the same phase at these angles. It indicates the higher degree of crystallization of the structure [18];

- amorphous phase arc within the range $2 \Theta=5$ - 11,78 in X-ray pattern of sample №2, which contains most of peaks related to $\mathrm{CSH}$ phase, is more intensive.

Comparison of X-ray patterns from $2 \Theta=15,7^{\circ}$ (peak of ettringite in the Fig. 1) to $2 \Theta=$ $42,0^{\circ}$ reveals their identity (intensity values of the phases under consideration are nearly the same - Fig. 1). Peak of CSH phase within this range is displaced to $2 \Theta=30,9^{\circ}$; peak for sample №1 increases at $2 \Theta=25,64^{\circ}$.

Reviewing the main differences of X-ray patterns of control samples with different flexural strength, it should be noted that $\mathrm{R}_{\text {изг }}$, apparently is related to amorphous nature of the emerging structure and to morphology of generated hydrates, which has been already revealed in [22 - 25]. With regard to these observed features, the X-ray diffraction patterns of samples subjected to early loading were compared with previously known strength characteristics (according to Table 2), shown in Fig. 2. 


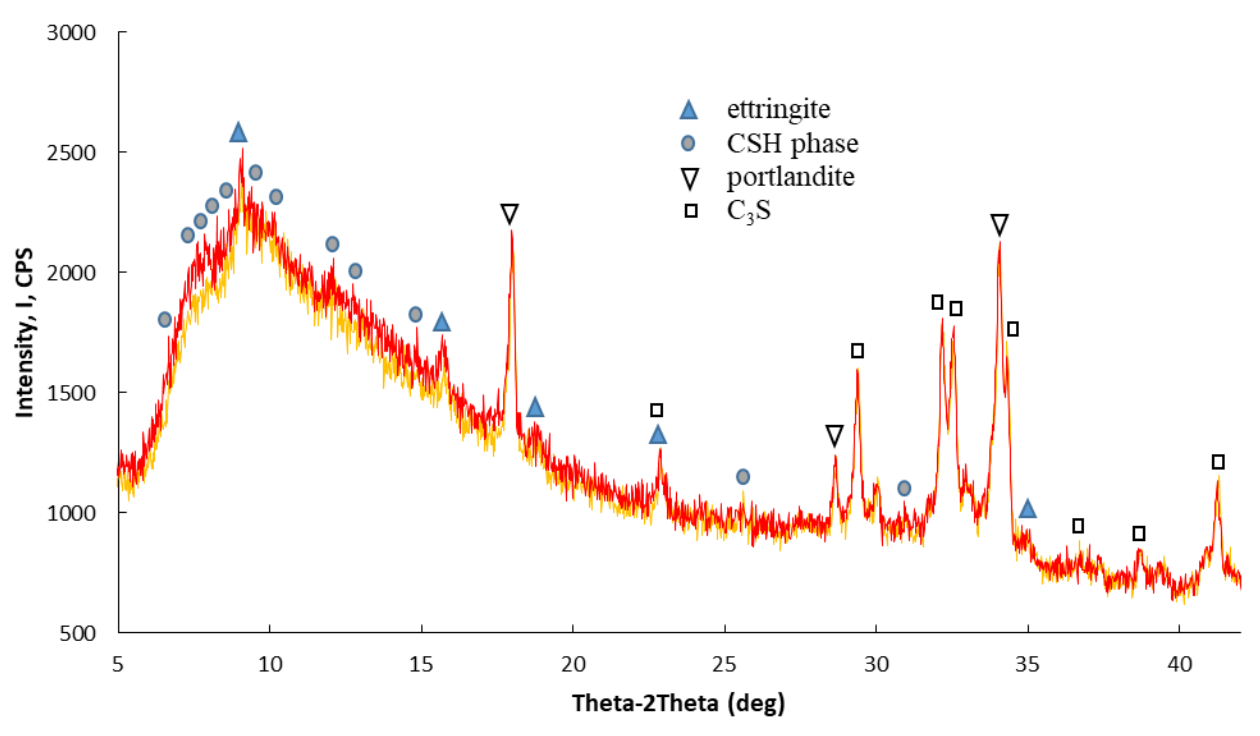

loaded $1 \longrightarrow$ loaded 2

Fig. 2 X-ray diffraction patterns of samples subjected to early loading (strength characteristics are given in the Table 2)

For sample №2 of cement stone subjected to early loading, which had shown the higher flexural strength when tested, the main peak of Portlandite at $2 \Theta=17,94^{\circ}$ had the higher intensity, as well as in the Fig. 1. For ettrigite sharpness of the peak at $2 \Theta=9,04^{\circ}$ in according to review of sample №2 is more extreme, which could also signal more intensive crystallization in samples with higher flexural strength. There is also change in the amorphous phase arc which is $2 \Theta=5-11,78^{\circ}$. When comparing, it is evident that the arc is raising in line with increase of flexural strength, i.e. when the structure of the cement stone becomes more amorphous. Overlaying of four X-ray patterns representing samples subjected to early loading and control samples of the same composition is shown in Fig. 3.

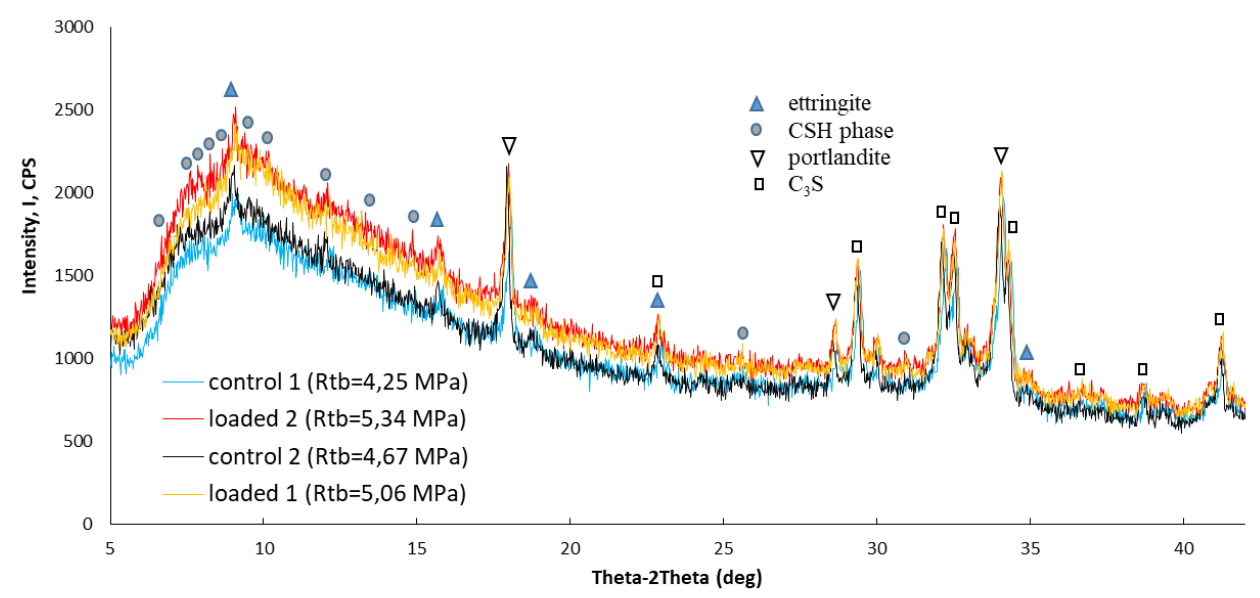

Fig. 3 Overlaying of curved representing samples subjected to early loading and control samples (strength characteristics are given in Table 2) 
As the intensity of the diffraction peaks increases, the $\mathrm{x}$-ray diffraction patterns are set up from the cement stone with the minimum $\mathrm{Rtb}=4,25 \mathrm{mPa}$ ("control sample" 1 ) to sample № 2 subjected to early loading with maximum flexural strength (Rtb $=5,34 \mathrm{mPf}$ ). There is a lift of amorphous phase arc of samples subjected to early loading (Fig. 3). Increase of amorphous properties observed in samples subjected to early loading due to hardening under compression, apparently, can be attributed to increase of absorbed bound water in the structure (as it is mentioned in [26]) as well as to formation of additional amorphous hydrates $\mathrm{CSH}$ (in particular, low-basic CSH-I with more amorphous structure, which are more difficult to detect by $\mathrm{x}$-ray phase analysis [27]).

To identify differences between crystalline and amorphous-crystalline calcium hydrosilicates, $\mathrm{X}$-ray phase analysis has been performed within a narrow range of angles $2 \Theta$ $=5-16^{\circ}$ (Fig. 4).

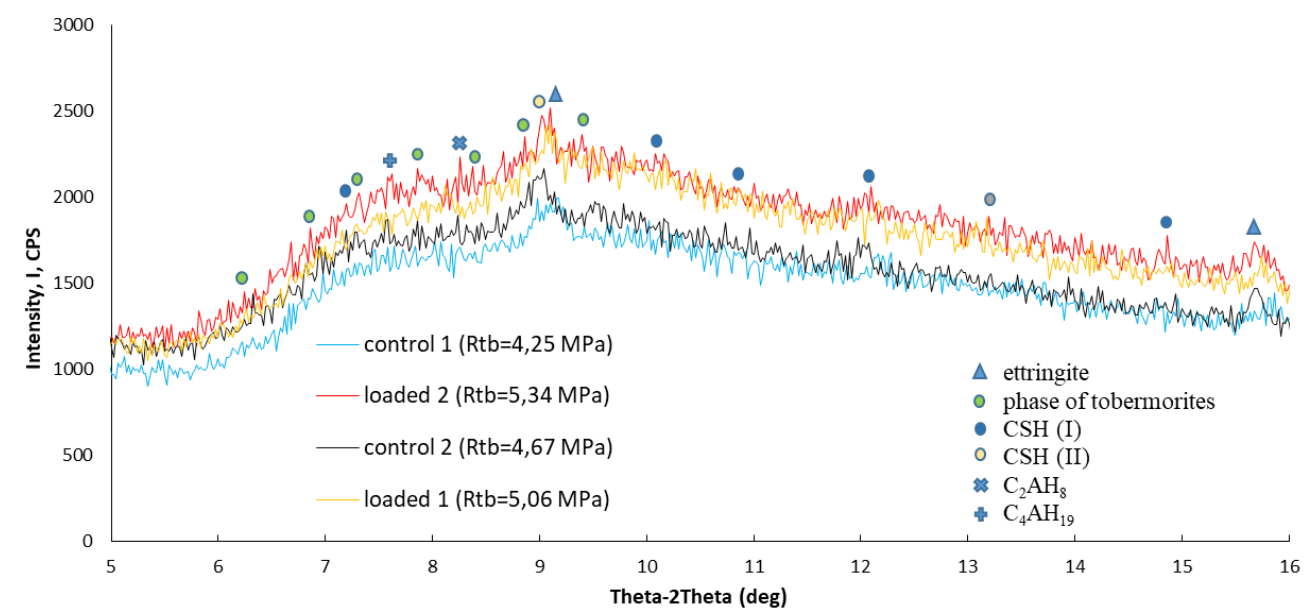

Fig. 4 Amorphous phase arc of control and subjected to early loading samples

When X-ray diffraction patterns of samples with different tensile strengths at bending, i.e. flexural strength, (see Figure 4) are overlaid, the maximum arc lift occurs in a sample of

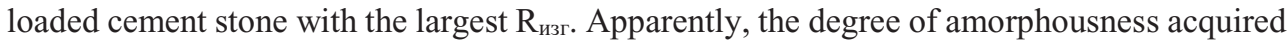
by the structure can influence the flexural strength.

Of particular interest is the angle range from $2 \Theta=6,8^{\circ}$ to $2 \Theta=8,48^{\circ}$. Here we can see the peaks of the crystalline hydrosilicates of the tobermorite group of $\mathrm{C}_{4} \mathrm{~S}_{5} \mathrm{H}_{5}$ and $\mathrm{C}_{5} \mathrm{~S}_{6} \mathrm{H}_{5}$ type, i.e. crystalline tobermorites with with interplanar distances $d=12,5 \AA ; 11,5-11,3 \AA[19$ $20,27]$, hexagonal hydroalluminate $\mathrm{C}_{2} \mathrm{AH}_{8} \mathrm{c} \mathrm{d}=10,7 \AA$, nineteen-hydrate hydroalluminate of $\mathrm{C}_{4} \mathrm{AH}_{19}$ type. Low-basic hydrated silicate $\mathrm{CSH}$ (I) has a broad peak with $\mathrm{d}=12,3 \AA$, which indicates amorphousness of phase.

Within the angle range from $2 \Theta=12,0^{\circ}$ to $2 \Theta=15,0^{\circ}$ an increase of the intensity of the diffraction maximum is also obvious. This range includes peaks of CSH (I) c d=7,32 $\AA$; $12,5 \AA ; 5,94 \AA$. High-basic hydrated silicate CSH (II) has peak starting at $\mathrm{d}=9,8 \AA$ and lifting to $2 \Theta=8,82^{\circ}$.

The height of the peaks of ettringite at angles from $2 \Theta=9,14^{\circ}$ to $2 \Theta=15,7^{\circ}$ is increasing with the growth of flexural strength while width of the peaks becomes narrower (Fig. 4).

To clarify the surveillance data obtained in the course of X-ray phase analyze, thermal analyze has been performed. The results of thermal analyze are presented in Fig. 5. The 
interpretation of the thermal effects on the thermograms is based on the reference data given in the works [19-20,28].

Shape of curves representing all the four samples is similar. Plot of the sample №1 of cement stone loaded at the early stage is located a bit lower. However, however, differentialscanning curves (DSC) reveal that it is close enough to sample 2 of cement stone loaded at the early stage. For ease of interpretation of the mass loss in the specific temperature intervals data is summarized in Table 3. The Table below contains temperature intervals in which occur endo- and exoeffects related to the phases of cement stone under consideration [28].

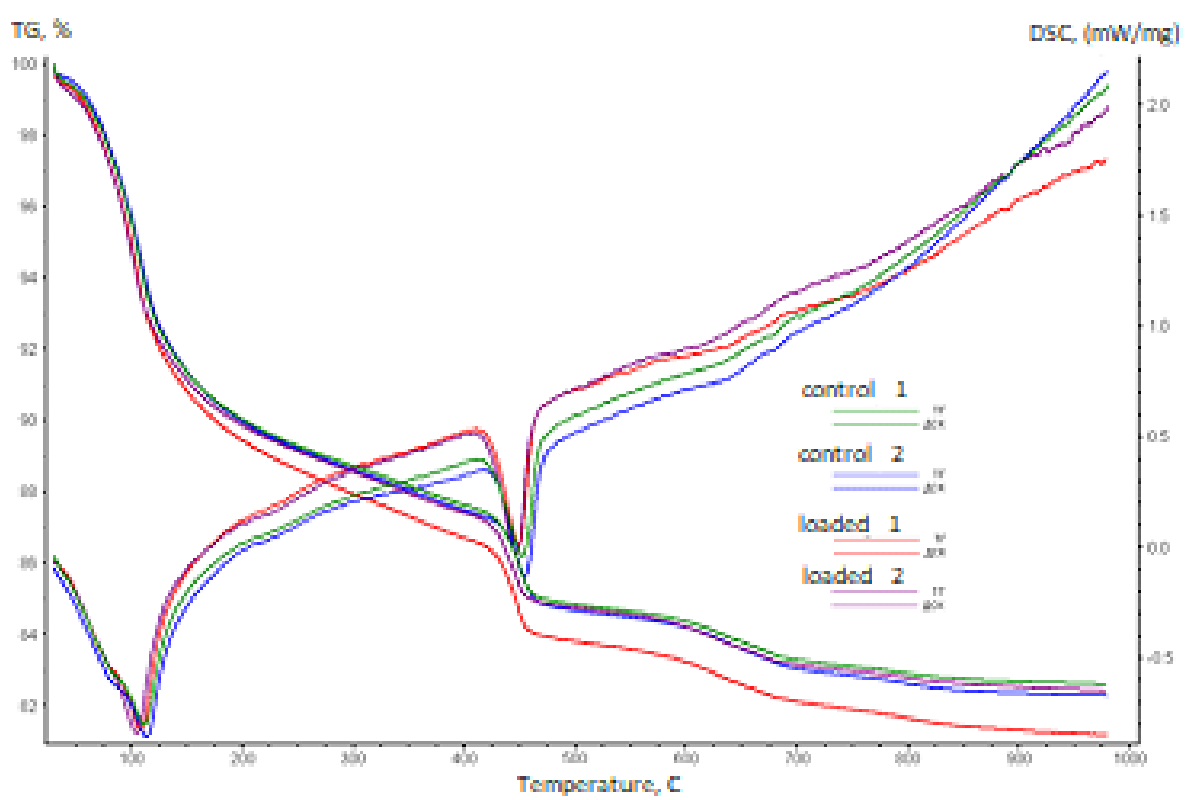

Fig. 5 Comparison of thermograms obtained from samples of control and early-stage loaded cement stone with different flexural strength (according to Table 2)

Shape of curves representing all the four samples is similar. Plot of the sample №1 of cement stone loaded at the early stage is located a bit lower. However, however, differentialscanning curves (DSC) reveal that it is close enough to sample 2 of cement stone loaded at the early stage. For ease of interpretation of the mass loss in the specific temperature intervals data is summarized in Table 3.

The Table below contains temperature intervals in which occur endo- and exoeffects related to the phases of cement stone under consideration [28].

Despite the change in amorphousness, the average mass loss up to $105^{\circ} \mathrm{C}$ for samples of control and loaded at an early stage samples is $8.13 \%$ with maximum variation $2.76 \%$. This indicates a similar amount of loosely bound water in all samples. In the temperature range from 130 to $400^{\circ} \mathrm{C}$, when endoeffects related to dehydration of ettringite and hydrated calcium silicate are mainly observed (CSH) [28], the average value of the mass loss for earlystage loaded samples was higher -4.86 versus 4.58 for control ones.

This observation correlates well with the increase of intensity rate of diffraction maximum of ettringite and hydrated silicates of the tobermorite group (which are characterized by thermal effects within the range $100-180^{\circ} \mathrm{C}, 230-240^{\circ} \mathrm{C}, 250-300^{\circ} \mathrm{C}$ ), as it is shown in Fig 2,3. 
Table 3 Mass loss in the course of thermal analyze

\begin{tabular}{|c|c|c|c|c|}
\hline \multicolumn{5}{|c|}{ Mass loss in the temperature interval, $\%$} \\
\hline $\begin{array}{c}0 \sim 105^{\circ} \mathrm{C} \\
\text { Unbound } \mathrm{H}_{2} \mathrm{O}\end{array}$ & $\begin{array}{r}130 \sim 400^{\circ} \mathrm{C} \\
\text { Ettringite and } \\
\text { CSH phase }\end{array}$ & $\begin{array}{c}400 \sim 450{ }^{\circ} \mathrm{C} \\
\text { Portlandite } \\
\mathrm{Ca}(\mathrm{OH})_{2}\end{array}$ & $\begin{array}{r}670 \sim 720^{\circ} \mathrm{C} \\
\mathrm{CSH} \text { (primarily } \\
\text { high-basic) }\end{array}$ & $\begin{array}{c}720 \sim 900{ }^{\circ} \mathrm{C} \mathrm{Calcite} \\
\text { CaCO3 } \\
\text { Crystallization of } \\
\text { wollastonite (exoeffect) }\end{array}$ \\
\hline 7,91 (control 1) & $4,62($ control 1$)$ & $2,28($ control 1$)$ & $1,38($ control 1$)$ & $0,94($ control 1$)$ \\
\hline 8,25 (control 2) & $4,55($ control 2$)$ & 2,30 (control 2) & $1,47($ control 2) & $0,96($ control 2) \\
\hline $8,32($ loaded 1$)$ & $4,93$ (loaded 1$)$ & $2,34($ loaded 1$)$ & $1,63$ (loaded 1$)$ & $0,99$ (loaded 1$)$ \\
\hline 8,06 (loaded 2) & 4,79 (loaded 2) & 2,24 (loaded 2) & 1,57 (loaded 2) & 0,91 (loaded 2) \\
\hline
\end{tabular}

A similar tendency is revealed within the range $670-7200{ }^{\circ} \mathrm{C}$, the mass loss in which refers to decomposition of high-basic hydrated silicates (i.e. CSH-II). Another useful criterion when estimating the content of hydrated silicates, especially the ones of the amorphous type (CSHI), is the exoeffect occurred at $830-8500 \mathrm{C}$, which corresponds to their crystallization into vollastonite. However, the superposition of the endoeffect from decarbonization of calcite $\mathrm{CaCO}_{3}$ may cause error in the assessment of the $\mathrm{CSH}$ phase basing on the exoeffect due to the crystallization of vollastonite [19].

\section{Conclusions}

1) comparison of samples of cement stone showed lift of the arc of $X$-ray patterns within angle range $2 \Theta=5-16^{\circ}$ in parallel with increase of strength;

2 ) there is a higher resolution of the peaks of crystalline tobermorite and ettringite, as well as of the broad peaks of phase CSH (I), in the cement stone subjected to early loading;

3 ) an increase in the tensile strength in bending (flexural strength) of loaded samples may be due to a change in the amorphousness of the structure, deformed by load application [1, 23, 25];

4) assessment of endoeffects indicates a slight difference in the content of Portlandite in early-stage loaded samples and control ones.

\section{References}

1. A. V. Satalkin, Early Loading of Concrete and Reinforced Concrete in Bridge Construction (Avtotransizdat, 1956)

2. G. B. Goldin, Concrete and Reinforced Concrete 5, 227-230 (1964)

3. I. I. Ulitskii, I. A. Rusinov, Concrete and Reinforced Concrete 12, 435-440 (1956)

4. R. A. Melnik, Concrete and Reinforced Concrete 3, 132-137 (1964)

5. A. I. Semenov, S. I. Arzhanovsky, Concrete and Reinforced Concrete 12, 34-37 (1972)

6. E. M. Babich, L. P. Makarenko, Proceedings of high schools. Construction and architecture 3, 20-27 (1967)

7. A. V. Kosolapov, Proceedings of high schools. Construction and architecture 3, 98-103 (1976)

8. Yu. P. Inozemtsev, V. P. Varlamov, P. P. Budnikova, Proceedings of high schools. Construction and architecture 10, 53-55 (1989)

9. A. P. Vasiliev, N. G. Matkov, G. V. Murashkin, S. A. Butenko, I. V. Afanasyev, Concrete and Reinforced Concrete 11, 11-12 (1983) 
10. A. A. Afanasyev, A. V. Kurochkin, Academia. Architecture and Construction 2, 113118 (2016)

11. S. B. Koval, M. V. Molodtsov, Proceedings of SUSU 16, 15-17 (2011)

12. I. I. Shukenov, B. M. Chalabaev, A. E. Erkinbekov, Concrete Technology 2, 39-40 (2009)

13. M. Nehdi, A. M. Soliman, Construction Materials 164, 57-77 (2011)

14. P. Claisse, C. Dean, Construction Materials 166, 152-157 (2013)

15. J. Justs, J. Bajare, A. Korjakins, Construction Science 8, 50-57 (2013)

16. Yu. Yu. Galkin, S. A. Udodov, L. V. Vasilieva, Herald of Civil Engineers 3, 131-138 (2017)

17. Yu. Yu. Galkin, S. A. Udodov, L. V. Vasil'eva, Magazine of Civil Engineering 7, 114122 (2017)

18. K. Scrivener, R. Snellings, B. Lothenbach, A practical guide to microstructural analysis of cementitious materials ( $\mathrm{T} \& \mathrm{~F}$ Group, 2016)

19. L. M. Kovba, V.K. Trunov, Radiography (MSU, 1976)

20. V. S. Gorshkov, V. V. Timashev, V. G. Savelyev, Methods of physico-chemical analysis of binders (Vishcha shkola, 1981)

21. T. V. Kuznetsova, I. V. Kudryashov, V. V. Timashev, Physical chemistry of knitting materials (Vishcha shkola, 1989)

22. R. J. Pelleng, A. Kushima, R. Shahsavari, K. L. van Vliet, M. J. Buehler, S. Yip, F. - J. Ulm Proceedings of National Academy of Science (2009)

23. A. Bentur, N. B. Milestone, J. F. Young, Cement. and Concrete. Research 8, 721-732 (1978)

24. J. J. Brooks Concrete and masonry movements (Elsevier, 2015)

25. F. J. Ulm, O. Coussy ASCE Journal of Engineering Mechanics 122, 1123-1132 (1996)

26. T. V. Kuznetsova, Alitinform: Cement. Concrete. Dry mixes 2, 8-24 (2008)

27. H. Taylor Chemistry of cement (Mir, 1996)

28. E. Ya. Yokhelson, N. G. Korsak, A. V. Satalkin, P. B. Tarasov Physico-mechanical properties of concrete (Stroyiizdat, 1939) 